\section{REFERENCES}

1 Capelastegui A, Espana PP, Quintana JM, et al. Validation of a predictive rule for the management of communityacquired pneumonia. Eur Respir J 2006; 27: 151-157.

2 Lim WS, van der Eerden MM, Laing R, et al. Defining community acquired pneumonia severity on presentation to hospital: an international derivation and validation study. Thorax 2003; 58: 377-382.

3 World Population at a Glance: 1998 and beyond. U.S. Dept of Commerce, Economics and Statistics Administration, Bureau of the Census, IB /98-4, International Brief, 1999. www.census.gov/ipc/prod/wp98/ib98-4.pdf. Date last accessed: March 212006.

4 Woodhead MA. Pneumonia in the elderly. I Antimicrob Chemother 1994; 34: Suppl. A, 85-92.

5 Myint PK, Kamath AV, Vowler SL, Maisey DN, Harrison BD. The CURB (confusion, urea, respiratory rate and blood pressure) criteria in community-acquired pneumonia (CAP) in hospitalised elderly patients aged 65 years and over: a prospective observational cohort study. Age Ageing 2005; 34: 75-77.

6 Neill AM, Martin IR, Weir R, et al. Community acquired pneumonia: aetiology and usefulness of severity criteria on admission. Thorax 1996; 51: 1010-1016.

7 Kamath A, Pasteur MC, Slade MG, Harrison BD. Recognising severe pneumonia with simple clinical and biochemical measurements. Clin Med 2003; 3: 54-56.

8 Warren JL, Bacon WE, Harris T, McBean AM, Foley DJ, Phillips C. The burden and outcome associated with dehydration among United States elderly, 1991. Am J Public Health 1991; 84: 1265-1269.

9 Ewig S, Torres A, Woodhead M. Assessment of pneumonia severity: a European perspective. Eur Respir J 2006; 27: 6-8.

\title{
Flawed interpretative strategies for lung function tests harm patients
}

\section{To the Editors:}

"The devil's in the details" of the new American Thoracic Society (ATS)/European Respiratory Society (ERS) document regarding the interpretation of pulmonary function test (PFT) results [1]. As a member of the Task Force, I was happy for the opportunity to help standardise the way in which clinically important PFTs are performed and interpreted. Unfortunately, the group spent almost all of the 3 yrs reaching an agreement (or compromise) on the mechanics of making accurate spirometry, diffusing capacity of the lung for carbon monoxide and lung volume measurements, but left inadequate time to thoroughly discuss the more important but controversial aspects of interpretation. A consensus was not reached, and thus, should not be inferred by publication of the document. In my opinion, the strategy for interpreting the presence of "obstructive abnormalities" is the detail with the highest potential for causing harm to patients.

This new strategy suggests interpreting a low forced expiratory volume in one second (FEV1)/vital capacity (VC) with a normal FEV1 as mild obstruction (see fig. 2 and table 6 in [1]). Previous documents have considered this pattern as a "normal physiological variant," normal, or borderline abnormal [2], since no associations with clinical disease or increased risk of future disease have been established for this pattern. In 2001, the Global Initiative for Chronic Obstructive Lung Disease (GOLD) guidelines [3] were the first to consider this pattern (post-bronchodilator) to indicate mild COPD (even in patients without respiratory symptoms), followed by the ATS/ERS guidelines [4], but neither provides any evidence for this change. The latest British Thoracic Society guidelines for mild COPD [5], however, used the traditional definition of a low
FEV1/forced vital capacity (FVC) and an FEV1 $<80 \%$ of predicted. The apparent COPD prevalence rate is doubled when this new definition is applied to adults; and even tripled in those aged $>65$ yrs [6].

The new strategy also suggests interpreting the common "nonspecific" pattern of normal FEV1/VC with a low FVC (sometimes called spirometric restriction) as mild obstruction (fig. 2 in [1]), at least when the total lung capacity is normal (ruling out true restriction of lung volumes). However, I'm unaware of any studies describing the clinical correlates or subsequent outcomes of groups of patients with this pattern.

If widely followed, I believe that this new strategy will: 1) more than double the apparent prevalence of mild airway obstruction; 2) increase the rate of falsely positive interpretations; 3) raise the number of prescriptions for inhaled medications for those who won't benefit from them; and 4) increase the financial, physical and psychological side-effects of these medications. A recent study from 50 sites in Europe [7] found that $75 \%$ of study participants with mild COPD (GOLD stage II) were already taking inhaled corticosteroids, despite the fact that no inhaled medication has been found to improve clinical outcomes in patients with an FEV1 $>50 \%$ pred [8].

Like others before it, this new interpretative strategy is likely to be programmed into the spirometers purchased by both pulmonologists and primary care providers. When the computerised interpretation says "mild obstruction," most doctors believe it.

\section{P. Enright}

College of Public Health, The University of Arizona, Tucson, AZ, USA. 


\section{REFERENCES}

1 Pellegrino R, Viegi G, Brusasco V, et al. Interpretative strategies for lung function tests. Eur Respir J 2005; 26: 948-968.

2 American Thoracic Society Lung function testing: selection of reference values and interpretative strategies. Am Rev Respir Dis 1991; 144: 1202-1218.

3 Pauwels RA, Buist AS, Calverley PM, Jenkins CR, Hurd SS, GOLD Scientific Committee. Global strategy for the diagnosis, management, and prevention of chronic obstructive pulmonary disease. NHLBI/WHO Global Initiative for Chronic Obstructive Lung Disease (GOLD) Workshop summary. Am J Respir Crit Care Med 2001; 163: 1256-1276.

4 Celli BR, MacNee W, ATS/ERS Task Force. Standards for the diagnosis and treatment of patients with COPD: a summary of the ATS/ERS position paper. Eur Respir J 2004; 23: 932-946.

5 National Collaborating Centre for Chronic Conditions Chronic obstructive pulmonary disease. National clinical guideline on management of chronic obstructive pulmonary disease in adults in primary, secondary care, Thorax 2004; 59: Suppl. 1, 1-232.

6 Viegi G, Pedreschi M, Pistelli F, et al. Prevalence of airways obstruction in a general population: European Respiratory Society vs American Thoracic Society definition. Chest 2000; 117: Suppl. 2, 339S-345S.

7 Decramer M, Rutten-van Molken M, Dekhuijzen PN, et al. Effects of $\mathrm{N}$-acetylcysteine on outcomes in chronic obstructive pulmonary disease: a randomised placebo-controlled trial. Lancet 2005; 365: 1552-1560.

8 Minnesota Evidence-based Practice Center of the Agency for Healthcare Research and Quality (AHRQ). Use of spirometry for case finding diagnosis, and management of chronic obstructive pulmonary disease (COPD). www.ahrq.gov/ clinic/tp/spirotp.htm Last updated: August 2005. Last accessed: January, 5: 2006.

DOI: $10.1183 / 09031936.06 .00009006$

\section{From the authors:}

We would like to thank P. Enright for giving us the opportunity to clarify some issues raised by the recently published interpretative strategies for lung function tests [1]. P. Enright's letter is important in that it reinforces our shared belief that guidelines are always relative and complete consensus is a utopian ideal. It also clarifies why he chose not to be listed among the authors of this section, and shows the difference in perception of time among individuals. Our records show that there was a Task Force meeting in Stockholm in 2002, which was almost entirely devoted to the divergent opinions about interpretation, most of them raised by P. Enright. Over the next year, we had a number of additional discussions by telephone and e-mail before a final vote was taken in Vienna in 2003.

The first point raised by $\mathrm{P}$. Enright addresses the interpretation of a low forced expiratory volume in one second (FEV1)/vital capacity (VC) when the FEV1 is normal. We recognise that figure 2 and table 6 do not specifically include the possibility that such a pattern may be a normal variant, but we are confident that the average reader will be careful enough to note this possibility is clearly included in the accompanying text. The text also stresses that an interpretation of airflow obstruction will depend on the prior probability of lung disease and on additional tests. We share P. Enright's concern that relying only on FEV1/VC to establish treatment may be wrong, but we believe the possibility of disease must be considered in subjects with this pattern. In fact, although his letter claims "no associations with clinical disease or increased risk of future disease have been established for this pattern", another of his recent publications notes that this very spirometric pattern is associated with an increased risk of death [2]. It should also be noted that in particular populations, e.g. athletes with large lungs, this pattern may be present due to unequal growth of airways and lung parenchyma, whereas in asthmatic patients this may be due to airway narrowing. Distinguishing between these two conditions is an imperative task to help patients.

P. Enright also questions whether the characterisation of the pattern of normal FEV1/VC with a low VC and normal total lung capacity (TLC) is consistent with airflow obstruction. This concern appears to be based mostly on the lack of studies of clinical correlates and outcomes associated with this pattern, as if studies on lung mechanics should not count much in interpreting lung function tests. A number of studies have indeed shown that a number of asthmatics exhibit a similar decrease in FEV1 and VC or FVC after they have been exposed to inhaled agents that are known to narrow or close the airways without a change in TLC $[3,4]$. This has also been reported in chronic airflow obstruction [5] and the mechanism has been reproduced in healthy subjects [6, 7]. Altogether, these data are the foundation of the document's cautious statement that a normal FEV1/VC with low FEV1 and normal TLC may be consistent with airflow obstruction, an interpretation offered in the 1993 European Respiratory Society (ERS) guidelines on lung function testing [8]

We agree that there is a risk for the over-treatment of chronic obstructive pulmonary disease (COPD), but we believe the major part of this risk is not in the interpretative strategies published by the American Thoracic Society (ATS)/ERS (and supported by most of the Task Force members). We believe the suggestion to use the statistical lower limit of normal for FEV1/ $\mathrm{VC}$ and not per cent of predicted or fixed ratio to diagnose obstructive abnormalities is one of the real advantages of these guidelines. It will reduce the number of false-positive diagnoses as compared with using the Global Initiative for Chronic Obstructive Lung Disease or ERS/ATS COPD guidelines.

It is unlikely that a single interpretive strategy will work for all patients at all times, given the diversity of respiratory disorders that may be encountered. Likewise, persons with responsibility for the interpretation of spirometric tests must recognise this fact. Furthermore, it is our expectation that those who interpret spirometry tests have appropriate training and experience to do so. These guidelines are not "cookbooks". 